\title{
Korean Sports Crime and Its Responsibility for the Enactments of Sports Law
}

\author{
Jisu Kim, Daesu Ha, Sungwon Son, \& Jaegyun Kim \\ Hanyang University, South Korea
}

\section{Introduction}

Sports are a significant part of people's lives around the world. According to modern sports theory, sports are defined as "the sum of physical activities as games and play including competition" (Ryu, 2001, p.11). In Korea, along with the expansion of various areas (i.e., education, economy, etc.), improvements in sports are being made at the national and cultural level. Accordingly, sports-related laws are also being reorganized by enacting important principles (Kang, 2005). The purpose of this paper is to discuss the history and theory of sports law and sports crimes in Korea by referring to existing studies.

Keywords: Korean crime theory, Korean sports law, Korean criminal law

\begin{tabular}{lr}
\hline Article History & Corresponding Author \\
Received 20 September 2020 & haesu Ha \\
Accepted 10 October 2020 & hadaesugo @daum.net \\
Published 31 October 2020 & School of Law \\
Available online 31 December 2020 & Hanyang University, South Korea \\
https://doi.org/10.47544/johsk.2020.1.1.20 & \\
\hline
\end{tabular}

\section{Methods}

First, a literature review was widely conducted to examine the concepts and etymology of sports through exploring existing studies. Next, the concepts and histories of Korean sports law were investigated in accordance with its development in the past few decades. Finally, the theory of Korean sports crime and its responsibility for the enactment of sports laws were established and described.

\section{Results}

History of Korean Sports Law

Since the introduction of sports into Korea more deeply, laws have developed alongside their growth. As the importance of sports was recognized in the 1960s, related laws were enacted at the government level (Shin \& Jang, 2010). Many studies note that a turning point in Korean sports occurred in the 1980s; sports became more popular with the successful hosting of the Asian Games and Olympic Games in the 1980s (Yeon et al., 2018; Kang, 2005). Since then, professional sports have been established and expanded. Article 1 of the Korean National Sports

\section{Journal of Health Sports \& Kinesiology | ISSN 2692-9864 | www.johsk.com}


| 2020 | Volume 1 | Issue 1 | The Journal of Health, Sports, and Kinesiology |

Promotion Act, which is a representative law of the Sports Act, stipulates, "The purpose of the Act is to contribute to the promotion of Korean national sports, to promote the physical strength of the people, to cultivate the healthy spirit of the people, and to promote the Korean national prestige through physical education" (Yeon, 2015). Next, Article 1 of the Act on the Installation and Utilization of Sports Facilities stipulates that, "it aims to encourage the installation and use of sports facilities, to develop the sports facilities business, and for contribution to the promotion of Korean national health" (Yeon, 2015). In addition to sports laws, administrative laws include sports-related clauses. Examples include the Act on Welfare of Persons with Disabilities, the Korean National Health Promotion Act, the Juvenile Protection Act, and the Basic Youth Act (Lee, 2005).

\section{Theory of Korean Sports Crime}

Crime theory refers to the nature of crime, which is the basis of punishment. Crime theory has a subjective and an objective side (Shin, 2013; see Table 1). Objectivist crime theory emphasizes the objective facts of crime, in which the subject and the situation become one. The objective aspect means actions and results. In contrast, the subjective aspect focuses on understanding the person who committed the crime.

Table 1. Objectivism and Subjectivism in Crime Theory

\begin{tabular}{c|c}
\hline Objectivist & Subjectivist \\
\hline $\begin{array}{c}\text { Objective elements such as actions and consequences, } \\
\text { which are external facts in crime, are subject to penalty } \\
\text { evaluation. }\end{array}$ & $\begin{array}{c}\text { Subject of punitive evaluation of the actor's antisocial } \\
\text { character and criminal risk. }\end{array}$ \\
\hline
\end{tabular}

\section{Korean Sports Crime and Its Responsibility}

Sports crimes can be understood as sports-related criminal acts. Sports include various elements, such as competition, entertainment, and physical training, and sports accidents are those that occur during these physical activities or in connection with a sporting event or competition (Lee, 2005). The most frequent crimes that occur in sports are deliberate foul, violence, gambling/betting, and sometimes even murder. When a crime occurs, the victim and the perpetrator each have their own responsibilities, which can be divided into criminal responsibility and judicial responsibility (Lee, 2019). In general, liability for compensation arises when damage is caused by illegal activities (Shin, 2006).

\section{Discussion}

In the field of sports, the autonomous norms that are recognized by authorized associations are socially acceptable. In particular, crimes occurring in sports can be judged from the perspective of general crime theory based on the sport's personality, characteristics, or rules. Therefore, it is essential to discuss the range of autonomous recognition within the realm of sports (Shin, 2006). For example, if during a tennis game a ball hit by a racket bounces and hits a person's eyes, causing injury, it is necessary to decide whether this was an injury or a crime. Also, hitting a person in a boxing game is not a crime because players agree with boxing rules, and the rules are socially sanctioned. A clear definition of sports crime is required.

As the sports industry develops, sports crime increases. However, sports laws cannot keep up (Kang, 2005). For example, the scope of sports crime is not yet clear, so there is difficulty making a legal interpretation when a sports crime occurs. There is the need for a legal mechanism that can accurately overcome this ambiguity. According to survey data from Korea's Ministry of Culture, Sports and Tourism (2019), the Korean sports industry grew between 2016 and 2018 (see Figure 1), as did the number of cases of sports violence (National Human Rights Commission of Korea, 2019; see Figure 2). 


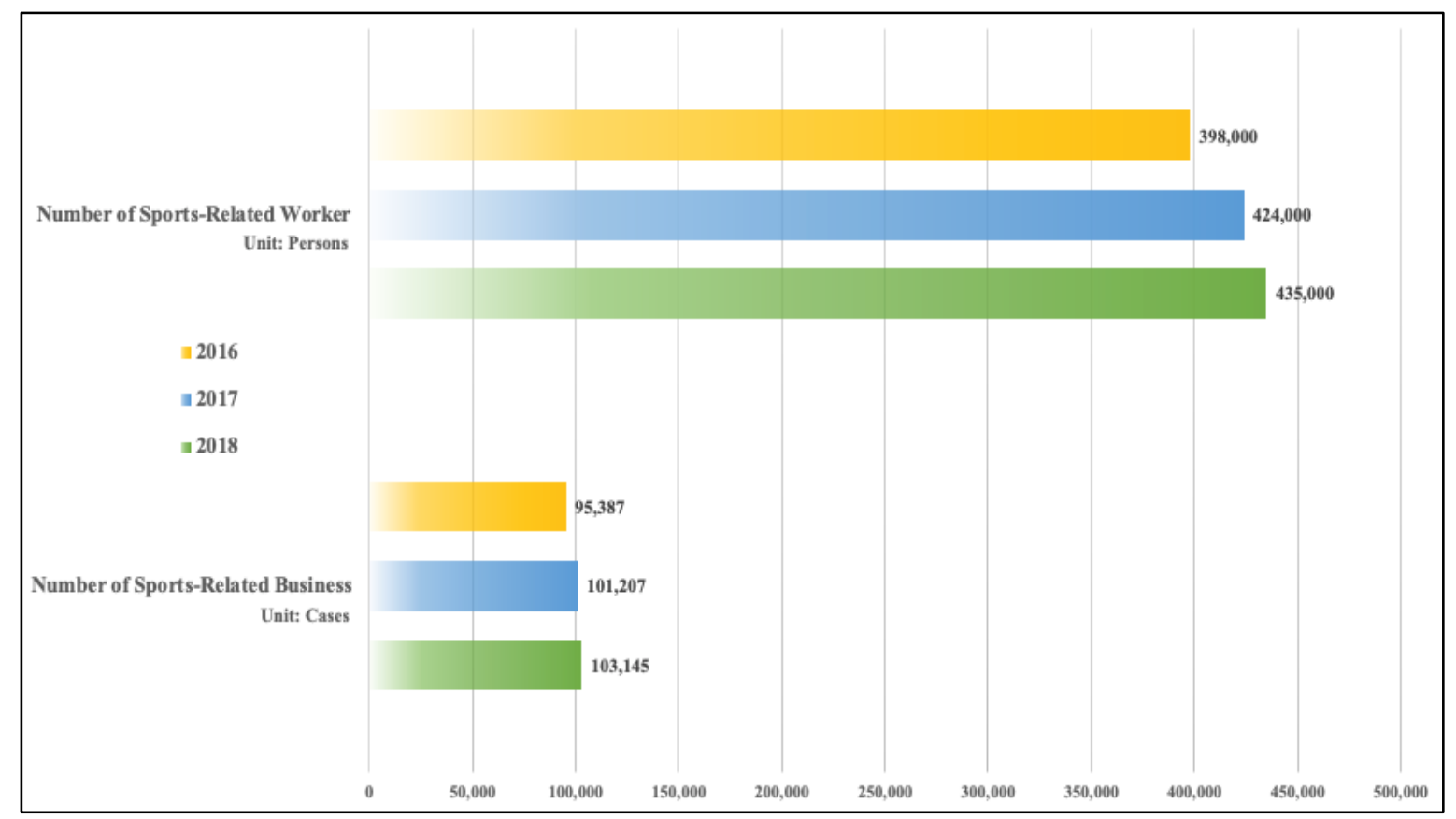

Figure 1. Korean Sports Industry: Development Status, 2016-2018 (Ministry of Culture, Sports and Tourism, Korea, 2019)

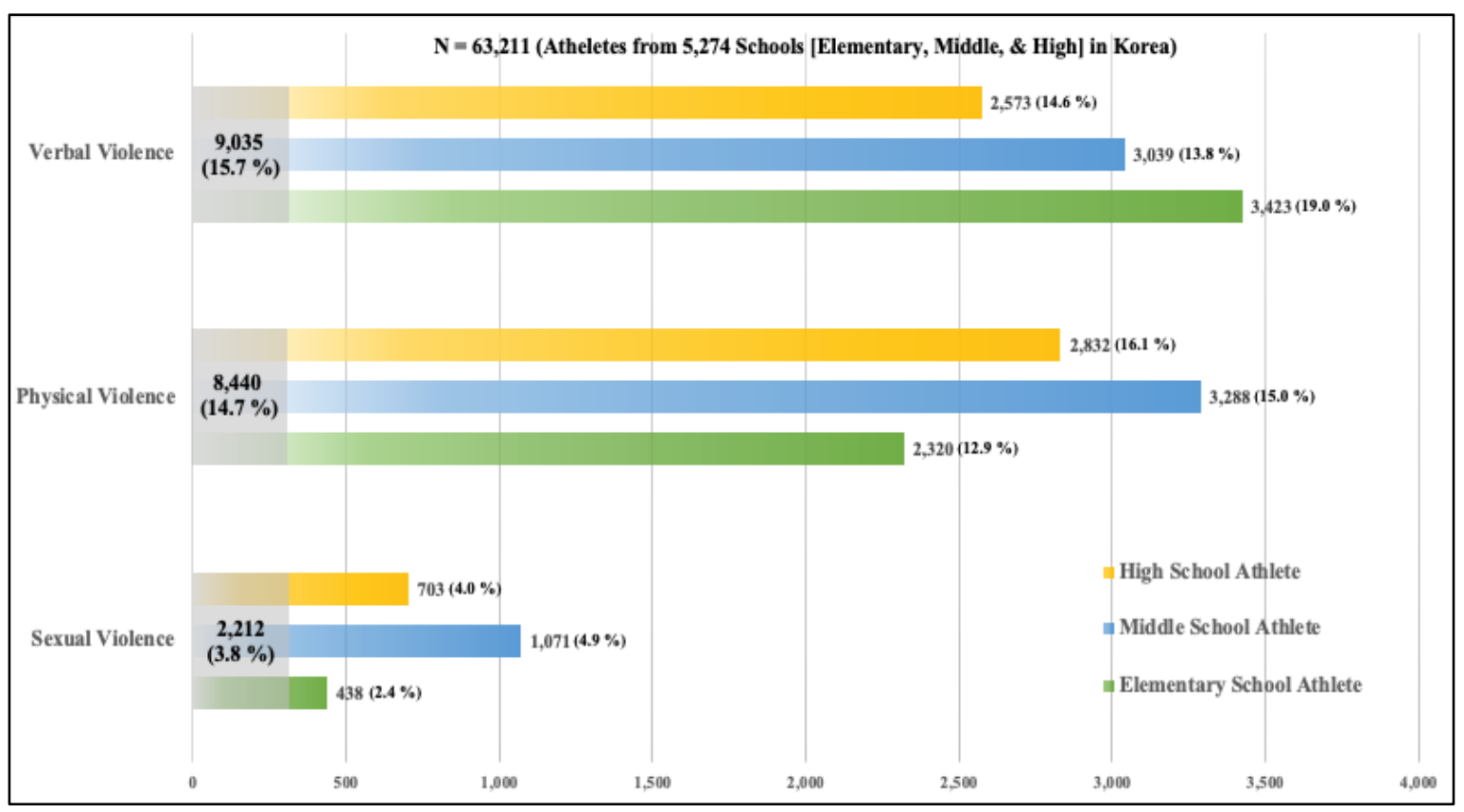

Figure 2. Korean Student Athletes' Experience of Violence, 2016-2018 (National Human Rights Commission of Korea, 2019)

\section{Journal of Health Sports \& Kinesiology | ISSN 2692-9864 | www.johsk.com}




\section{Conclusion}

In Korea, sports crimes are currently addressed by only a few general laws, such as Article 1 of the National Sports Promotion Act and Article 1 of the Sports Industry Promotion Act, that cannot deal with many different types of sports crimes. The field of sports will develop more and more, and it would lead to more crimes. It is highly required to strengthen and supplement sports laws to protect people's rights and interests, and by extension, the movement would create a healthier sports community.

\section{References}

Kang, K. (2005). Sports concepts, sports and laws in the constitution. The Korean Association of Sports Entertainment Law. Korea.

Lee, G. (2005) Study on the responsibility for illegal activities under sports law. Doctoral dissertation. Chosun University. KERIS RISS International Database.

Lee, J. (2019). Law man criminal law. Wilvis. Korea

Ministry of Culture, Sports and Tourism. (2019). Report of sports industry. Ministry of Culture, Sports and Tourism.

National Human Rights Commission of Korea. (2019). Report of Human rights survey for athletes 2016-2018. NHRCK.

Ryu, D. (2001). Study on the legal disputes of sports. Unpublished Doctoral dissertation. Keimyung University. KERIS RISS International Database.

Shin, D. (2013). The general law of the criminal law. Law and Literature. Korea.

Shin, S. (2006). A study on the legal responsibilities and sports Insurance of sports accidents. Doctoral dissertation. Keimyung University. KERIS RISS International Database.

Shin, H., \& Jang, H. (2010). Sports legal research. Korean Academic Information. Korea.

Yeon, G. (2015). Legislative issues of fairness and integrity in sports games-centered on legal responsibility for matchfixing. Sports Entertainment and Law, 18(4).

Yeon, G., Do, J., Jeong, S., \& Kim, H. (2018). Sports and law: Theory and practice of sports law. Formal Publishing. Korea 